MLM- 1287

TID-4500 (43rd Ed.)

Category - UC-2

Progress Reports

\title{
MOUND LABORATORY PROGRESS REPORT FOR AUGUST, 1965
}

J. F. Eichelberger

G. R. Grove

L. V. Jones
Date: August 20, 1965

Issued: February 23, 1966

The Mound Laboratory Progress Report, issued monthly, is intended to be a means of reporting items of current technical interest in research and development programs. To issue this report as soon as possible after the end of the month, editorial work is limited; and since this is an informal progress report, the results and data presented are preliminary and subject to change.

These reports are not intended to constitute publication in any sense of the word. Final results either will be submitted for publication in regular professional journals or will be published in the form of MLM topical reports

The previous reports in this series are.

MLM- 1274

MLM- 1268

$M L M-1266$

MLM- 1254

MLM- 1250

MLM- 1245
MLM- 1238

MLM-1231

MLM- 1227

MLM-1221

MLM- 1217

MLM- 1216

\section{MONSANTO RESEARCH CORPORATION}

A SUBSIDIARY OF MONSANTO COMPANY

MOUND LABORATORY

MIAMISBURG, OHIO OPERATED FOR

UNITED STATES ATOMIC ENERGY COMMISSION

U.S. GOVERNMENT CONTRACT NO. AT-33-1.GEN-53 
$\bullet$

.

$r$ 


\section{DISCLAIMER}

This report was prepared as an account of work sponsored by an agency of the United States Government. Neither the United States Government nor any agency Thereof, nor any of their employees, makes any warranty, express or implied, or assumes any legal liability or responsibility for the accuracy, completeness, or usefulness of any information, apparatus, product, or process disclosed, or represents that its use would not infringe privately owned rights. Reference herein to any specific commercial product, process, or service by trade name, trademark, manufacturer, or otherwise does not necessarily constitute or imply its endorsement, recommendation, or favoring by the United States Government or any agency thereof. The views and opinions of authors expressed herein do not necessarily state or reflect those of the United States Government or any agency thereof. 


\section{DISCLAIMER}

Portions of this document may be illegible in electronic image products. Images are produced from the best available original document. 


\section{TABLE OF CONTENTS}

Summary ..................... 5

\section{Radioelements}

Polonium-208/Polonium-209. . . . . . . . . . . . 9

Isotope Separation and Purification

Carbon Isotope Separation ................. II

Stable Gaseous Isotopes . . . . . . . . . . . . . . 12

Thermal Diffusion Research.................16

Helium Research ................... 22

Analytical and Instrumentation

Emission Spectroscopic Analysis . . . . . . . . . . . . . 29

Organic Research

Adhesive Shrinkage Studies............... 31 
○ 


\section{SUMMARY}

\section{RADIOELEMENTS}

Polenium-208/Polonium-209 X-ray diffraction patterns of an eight-month old sample of an isotopic mixture of polonium-208/polonium-209 were identical to the alpha phase of polonium-210 metal. Apparently, the face-centered cubic PbPo which grows acts as a seed for the growth of the alpha phase.

\section{ISOTOPE SEPARATION AND PURIFICATION}

\section{Carbon Isotope Separation}

Thermal Diffusion Material of molecular mass 18 has steadily accumulated in the 12-column, 8stage methane thermal diffusion system. Infrared analysis showed conclusively that this material was $\mathrm{C}^{13} \mathrm{H}_{3} \mathrm{D}$. It appears that the $\mathrm{C}^{13} \mathrm{H}_{3} \mathrm{D}$ forms in the thermal diffusion system by an exchange reaction between $\mathrm{C}^{13} \mathrm{H}_{4}$ and $\mathrm{C}^{12} \mathrm{H}_{3} \mathrm{D}$.

Chemical Exchange Two reaction runs were carried out using a mixed amine solution. The results were inconclusive because the carbamate did not dissociate completely. Two experiments were conducted using $\mathrm{N}$-(3-aminopropyl) cyclohexylamine in methanol. Some isotope separation was observed, but the carbamate crystallized during the runs.

\section{Stable Gaseous Isotopes}

Helium A 12-in. cylindrical charcoal trap reduced the tritium level of product helium-3 from 2.5 $\times 10^{-9} \%$ to $6.4 \times 10^{-11} \%$.

Neon The new three-column neon tube bundle is being checked in preparation for start-up. It should enrich $10 \%$ intermediate neon-21 to above $70 \%$.

Argon The five-stage argon cascade has built up an argon-38 peak of approximately $28 \%$. Drawoff of over $25 \%$ is expected to begin when the peak shifts to a gas port.

Krypton The fourth pass for enriching krypton-86 was made. Over $89 \%$ krypton-86 was accumulated. Additional processing to reach $95 \%$ is planned.

Xenon Thermal Diffusion: The new 24-column six-stage thermal diffusion cascade system constructed in two tube bundles (water jackets) was started using natural xenon as feed. A calcium trap is being installed to remove hydrogen accumulation. To date xenon- 124 has been enriched above $0.6 \%$ from the natural abundance of $0.096 \%$. 
Chromatography: The heats of adsorption of krypton and xenon on Linde Molecular Sieve 5A, 50/60 mesh have been calculated to be -1208 and $-1901 \mathrm{cal} / \mathrm{mole}$, respectively, based on separations using nitrogen as the carrier gas. Prelımınary measurements on molecular Sieve 13X, 50/60 mesh, Indicate the heat of adsorption to be about -1240 and $-1969 \mathrm{cal} / \mathrm{mole}$ for krypton and xenon, respectively, using nitrogen for the carrier gas. Calculations of nitrogen adsorption on Molecular Sieve 5A at the temperatures used indicate that the measured quantities may more nearly be heats of solution of krypton and xenon in nitrogen rather than heats of adsorption on the Zeolite.

\section{Thermal Diffusion Research}

Transport Coefficients Discrepancies between theory and experiment for recent thermal diffusion column experıments with neon can be explained by a stagnant gas barrier in the column. Experıments are in progress to test this hypothesis.

Collision Integrals The accuracy of the collision integrals has been investigated. The purpose of this investıgation was to desıgn a computer program to calculate collisıon integrals accurate to one part in 1000. The accuracy to which the angles of deflection and the cross sections must be calculated in order to obtain this accuracy in the collision integrals was determıned. The number of points in the integratıons necessary to obtain the required accuracy in the angles of deflection was then determined. Also, the accuracy of the interpolation method used to obtain intermediate values of the cross sections was studied.

Molecular Beam Scattering A narrow band velocity selector has been proposed for use in obtaınıng a monoenergetic beam of particles in the molecular beam scattering system. Design and construction of the selector are being studied. Theoretical performance figures were compared to previously used selectors described in the literature.

\section{Helıum Research}

Low Temperature Distıllation The possibilıty of maintaınıng a relatively constant level of liquid helıum in a pumped bath for use in the distillation separation of helium-3 and helium- 4 has been investigated. It has been found that a valve inside the cryostat at the end of the transfer tube may be used to control the flow of liquid helium to the bath. To avoid large losses of helıum from the bath, it is necessary for the stream of incoming gas or liquid to be directed away from the surface of the bath it appears that an intermediate dewar between the standard storage dewar and the cryostat will be necessary to provide a contınuous supply of helium to such a system

Vapor Pressure Thermometry Further consideration of the equations for gas flow in a tube has shown that an equation identical in form to the different Weber-Scmidt equation can be derived This equation is being developed to provide the proper thermomolecular pressure corrections to be used in helium-3 and helıum- 4 vapor pressure thermometry Four physical constants appear in the equation. (I) the fraction of molecules being diffusely reflected from the tube wall, (2) a geometrical factor containıng the ratıo of the tube area to volume, (3) deviation from maxwellıan velocity distribution of molecules makıng collisıons with the tube wall, (4) deviation from maxwellian velocity of molecules making collisions in the gas These four factors are beıng varıed to determıne the reason for differences in the measured thermomolecular pressure by different investigators

In addition, a simplified differential Weber-Schmidt equation which applied only to the high pressure region was investigated It was observed that the power Index used by Weber-Schmidt to calculate the viscosity did not adequately represent viscosity data presently available Two previously reported equations were 
Investigated by computer calculations and compared to the Weber-Schmidt equation and Mound experımental data The first equation used experimental viscosities and did not consider the term contaınıng the slip coefficient The second equation used a rigıd sphere model containıng the slip coefficient A comparison of calculation with the Weber-Schmidt equation and Mound experimental data demonstrated better agreement with the latter

\section{ANALYTICAL AND INSTRUMENTATION}

\section{Emıssion Spectroscopic Analysis}

Beryllium in Air A direct reader procedure was developed for the determination of beryllium in aır. It was possible to determıne I $\mu \mathrm{g}$ beryllium with an average deviation of $\pm 0.1 \mu \mathrm{g}$.

Impurities in Gold A direct reader procedure was developed which could detect impurities in gold at levels below $6 \times 10^{-5} \mathrm{mg}$.

\section{ORGANIC RESEARCH}

Adhesive Shrınkage Studies The total shrınkage of Eastman 910 adhesıve (methyl 2-cyano-acrylate) was determıned using thermal, free-radical and anionic polymerization conditions. When polymerization was conducted thermally or by free radical inıtıators, concurrent anıonıc polymerıcatıon was inhıbıted by the addıtion of boron trifluoride 2-acetic acid complex. The total shrınkage of the cured samples, determined from the initial and final densities of the material, was found to be independent of the method of polymerization. Total shrinkage in all cases was about $15.1 \%$. 
•

, 


\section{RADIOELEMENTS}

Basic and applied research is being conducted on a number of radioelements to determine their physical properties, to develop analytical techniques, and to study the basic radiochemistry involved. Of particular interest are alpha emitters, their decay chains, the ir isotopes, and their chemical homologs.

\section{POLONIUM-208/POLONIUM-209}

X-ray diffraction patterns of the isotopic mixture of polonium 208/209 metal (prepared in December 1964) were identical to the alpha phase (simple cubic) of polonium-210 metal; however, extremely weak lines of beta (rhombohedral) polonium are present. Thermal effects from self-heating of polonium- 208 and polonium209 are only $4 \%$ of polonium- 210 ; consequently, the rate of formation of lead is reduced from $0.5 \%$ per day to $0.02 \%$ per day. Apparently, the face-centered cubic lead polonide ( $P b P O$ ) which forms acts as a seed for growth of the simple cubic phase. The reappearance of the beta form after cooling may be the result of selfheating of the samples to temperatures above the $a \rightleftharpoons \beta$ transition temperature. The kinetics of this phase transformation as a function of temperature and time are presently being studied. 
-

- 


\section{ISOTOPE SEPARATION AND PURIFICATION}

Under the sponsorship of the Division of Research, Mound Laboratory is responsible for furnishing material to be used in the physical sciences to further the progress of science and technology in the public interest. After recovery, purification and concentration, research quantities of isotopes are furnished to installations for research programs in the physical sciences. Purified helium-3 and the isotopes of other noble gases and carbon-13 are available for distribution in research quantities. Methods of separation and purification are being studied.

\section{CARBON ISOTOPE SEPARATION}

Thermal Diffusion During most of the past year material of molecular mass 18 has steadily accumulated, as shown in Figure 1, at the product withdrawal point of the 12-column, 8-stage, methane thermal diffusion cascade. Inıtially this material was thought to be water vapor; however, recent experiments showed conclusively that the mass 18 fraction is $\mathrm{C}^{13} \mathrm{H}_{3} \mathrm{D} .^{1}$

The first evidence that the mass 18 was not water was acquired when a Drierite trap, inserted between columns 11 and 12, falled to affect the mass spectrographically determined mass 18 content. Samples were taken of a product bottle contaınıng approximately 1.5 liters of methane of greater than $90 \%$ mass 17 enrichment. The Figure I Accumulation of material of molecular mass $18 \mathrm{in}$ product bottle had been removed from the thermal difthe methane thermal diffusion cascade.

fusion system just before installation of the Drierite trap. One sample was submitted for mass spectrographic analysis, the other for infrared analysis. The results are given in Table 1. The mass spectrographic results
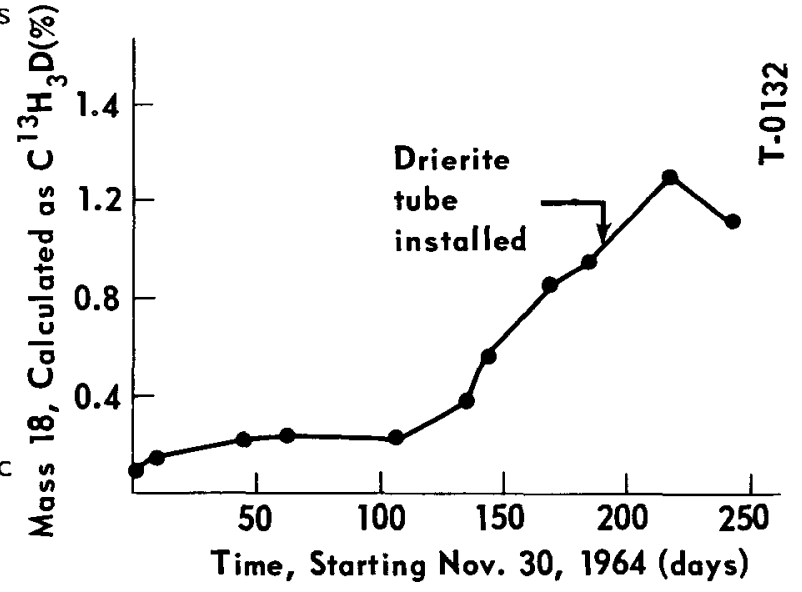
are computed on the assumption that the mass 18 fraction is $\mathrm{C}^{13} \mathrm{H}_{3} \mathrm{D}$. (The mass spectrograph is considerably less sensitive to $\mathrm{H}_{2} \mathrm{O}$ than to $\mathrm{C}^{13} \mathrm{H}_{3} \mathrm{D}$; hence, there is a large difference between mas 18 content calculated as $\mathrm{C}^{13} \mathrm{H}_{3} \mathrm{D}$ and mass 18 content calculated as $\mathrm{H}_{2} \mathrm{O}$.) It is quite clear from the infrared resul ts that the mass 18 fraction is indeed $\mathrm{C}^{13} \mathrm{H}_{3} \mathrm{D}$. Moreover, both instruments give essentially the same result for mass 18 . A composite isotopic analysis can be constructed from the two sets of results. This is also given in Table I.

The $\mathrm{C}^{12} \mathrm{H}_{3} \mathrm{D}$ in the product material is expected on the basis of the natural abundance of this species in the feed $g$ as, and it was unexpected that samples taken from the system previously showed only traces of $\mathrm{C}^{12} \mathrm{H}_{3} \mathrm{D}$ The amount of $\mathrm{C}^{13} \mathrm{H}_{3} \mathrm{D}$, however, cannot be accounted for in this way because the natural abundance of this species is small It appears, therefore, that exchange is taking place in the thermal diffusion cascade, and that the exchange results in the transfer of deuterium from $\mathrm{C}^{12} \mathrm{H}_{3} \mathrm{D}$ to $\mathrm{C}^{13} \mathrm{H}_{3} \mathrm{D}$. The detals of this process are at present unknown

${ }^{1} M L M=1254$. 
Table I

\section{Infrared and Mass Spectrographic Analyses of Methane Product}

Mass Spectrographic Analysis

$$
\begin{aligned}
& \text { Mass } 16 \\
& \text { Mass } 17 \\
& \text { Mass } 18 \\
& \text { Mass } 28 \text { (nitrogen) }
\end{aligned}
$$

Infrared Analysis

$$
\begin{aligned}
& C^{12} \mathrm{H}_{3} \mathrm{D} \\
& \mathrm{C}^{13} \mathrm{H}_{3} \mathrm{D}
\end{aligned}
$$

Composite Analysis

$$
\begin{aligned}
& C^{12} \mathrm{H}_{4} \\
& C^{12} \mathrm{H}_{3} \mathrm{D} \\
& \mathrm{C}^{13} \mathrm{H}_{4} \\
& \mathrm{C}^{13} \mathrm{H}_{3} \mathrm{D} \\
& \mathrm{N}_{2}
\end{aligned}
$$

Chemical Exchange The apparatus for the carbon dioxide-carbamate chemıcal exchange system was modified to include a new boiler-decomposer so that the decomposition efficiency would be maintained at high amine solution flow rates. The new boller incorporates a longer decomposer section which allows for more complete dissociation of the carbamate.

6.1

90.5

1.1

2.3

Two reaction runs were performed in the modified apparatus using a mixed amine solution. The solution was two molar in monoethanolamıne and 0.1 molar in diethanolamine with methanol as the solvent. The results were compared with runs carried out under similar conditions using the monoethanolamine alone. There was evidence of incomplete carbamate dissoclation in the mixed amıne runs; therefore, further investigation is necessary before any definite conclusion can be reached regarding the effectiveness of mixed amınes.

Another type of experiment was also initiated in the modified apparatus. A two molar solution of $\mathrm{N}$-(3amınopropyl) cyclohexylamıne in methanol was prepared and used as the exchanger in two separate runs. The first reaction run resulted in the crystallization

of the carbamate in the column; therefore, no isotope separation was observed. The second run was performed at a one molar concentration in methanol. Agaın some carbamate crystallızed. Some isotopıc separatıon was observed, however. It was concluded, therefore, that either a different solvent was required or that lower concentrations are necessary for the successful investigation of this amine.

\section{STABLE GASEOUS ISOTOPES}

Helium A short, cylındrıcal charcoal trap, I In. In diameter by 12 ın. Iong, was used to remove trace quantities of tritıum from product helıum-3. The initıal tritıum content was $2.5 \times 10^{-9} \%$. After the gas passed through the charcoal trap, which was maintained at liquid nitrogen temperature, the contamınation was reduced to $6.4 \times 10^{-11 \%}$ tritium.

Neon The piping on the three-column neon tube bundle has been completed. The system has been leak checked and is being pumped down. Shortly, the system will be started up, and experiments will be run to accumulate data to plot separation vs. pressure. In this manner, the proper operating pressure of the new system can be determıned, and these data can be compared to sımılar data calculated theoretically. The three-column tube bundle is expected to enrich neon-21 to $70-80 \%$ using $10-11 \%$ neon-2I feed from the present four-stage system. Figure 2 shows how the new system will be connected to the existing one. The end streams from the new columns will be recycled periodically to the original cascade.

Argon After 29 days of runnıng tıme with the five-stage argon cascade, $1100 \mathrm{ml}$ (the contents of an entıre column) of argon with an average argon-38 concentration of $17.0 \%$ was removed from the system. The argon38 in this column will be enriched further. The argon-36 product withdrawal rate was $2-2.5 \mathrm{ml} / \mathrm{hr}$, with the concentration gradually dropping to $99.0 \%$. The argon-38 column profile is shown in Figure 3 . The peak 


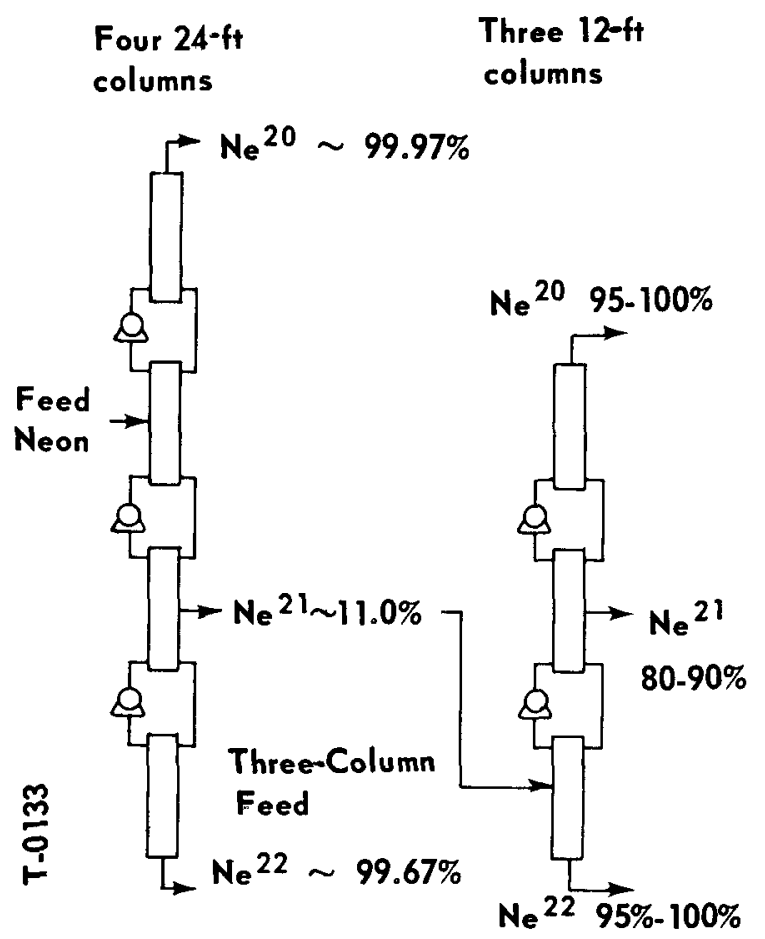

Figure 2. Complete neon system including the present four-column system on the left and the new three-column bundle on the right.

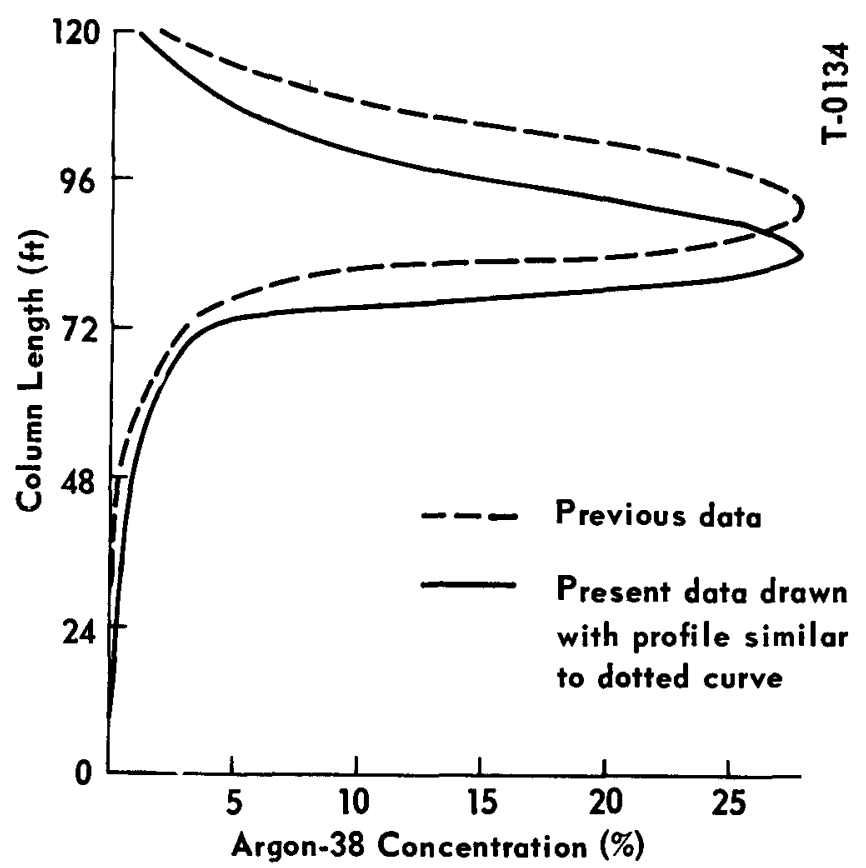

Figure 3. Argon-38 concentration as a function of column length in the $7-1-1-1-1$ argon cascade. concentration of $28 \%$ was estimated by drawing a profile similar to a profile from previous data. The peak concentration of $28 \%$ should have an accuracy of $28 \pm 3 \%$. The argon-38 of over $25 \%$ concentration will be drawn off after the peak shifts to a location close to a gas port.

Krypton In a two-column, two-stage thermal diffusion cascade, the third pass was completed for enriching krypton-84 and -86 . This pass enriched the krypton to $72 \%$ krypton- 86 . The fourth pass was equilibrated and flow started at about $3 \mathrm{ml} / \mathrm{hr}$ with the drawoff containing 89\% krypton-86. The fourth pass feed was reduced to $63 \%$ krypton- 86 in withdrawing 100 milliliters of fourth pass product of $88.9 \%$ krypton-86. This product also contained $4 \%$ xenon. In order to enrich the krypton-86 to $95 \%$ instead of $90 \%$, raffinate material is being reprocessed to obtain intermediate feed of $80 \%$ krypton-86, which will be used as feed for the final pass. Figure 4 shows the revised calculated final concentrations expected for initial concentrations in the circulating feed reservoir for various flow rates.

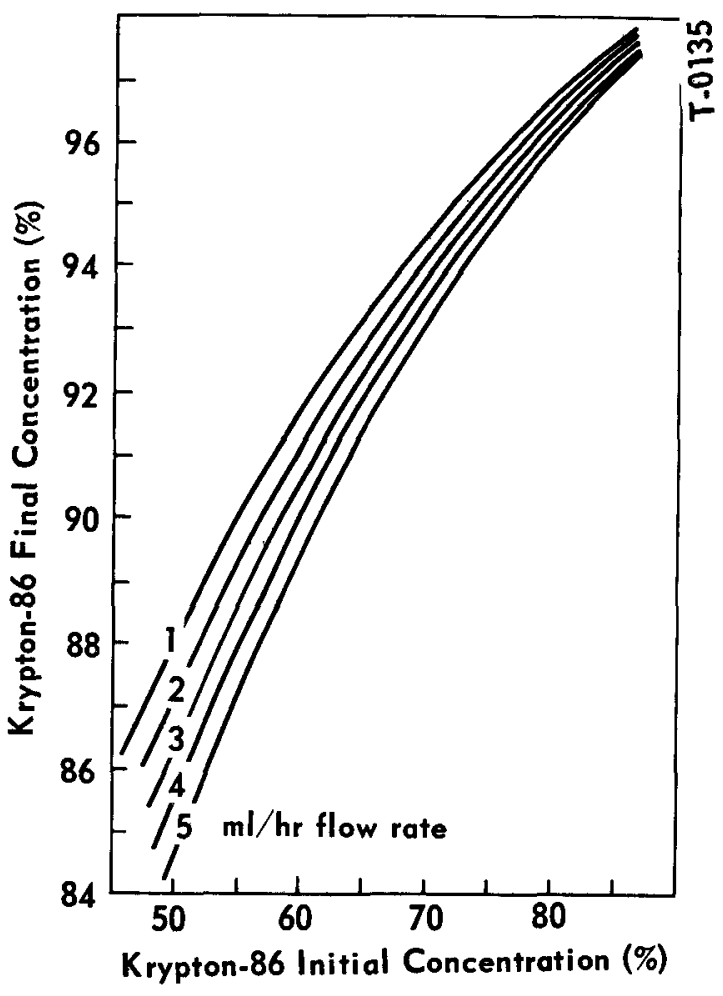

Figure 4. Calculated krypton-86 concentrations for various flow rates at $K_{c} / K_{d}=10$; $P=0.405 \mathrm{~atm}$. 
Thermal Diffusion Leak

checking of the 24-column, sixstage thermal diffusion cascade, having tube bundle construction with 18 columns in one shell and six columns in the second shell was completed. The columns, see Figure 5 , are $12 \mathrm{ft}$ long and have an 0.568 in. $(1.44-\mathrm{cm})$ cold-wall diameter and an $0.315-i n .(0.8-\mathrm{cm})$ hot-wall diameter. The system was filled with natural xenon in preparation for enriching the lightest stable xenon isotope, xenon-124. The operating conditions were set as follows:
Figure 5. Top and bottom sections of a xenon tube bundle column (dimensions in inches).

Feed pressure $\approx 4500$ torr

Column pressure $\approx 1000$ torr (stage 1); 1050 torr (stage 6)

Tubular heater temperature $\approx 750^{\circ} \mathrm{C}-780^{\circ} \mathrm{C}(10 \mathrm{amps})$

Interstage flow rate (circulation) $\approx 260 \mathrm{ml} / \mathrm{min}$

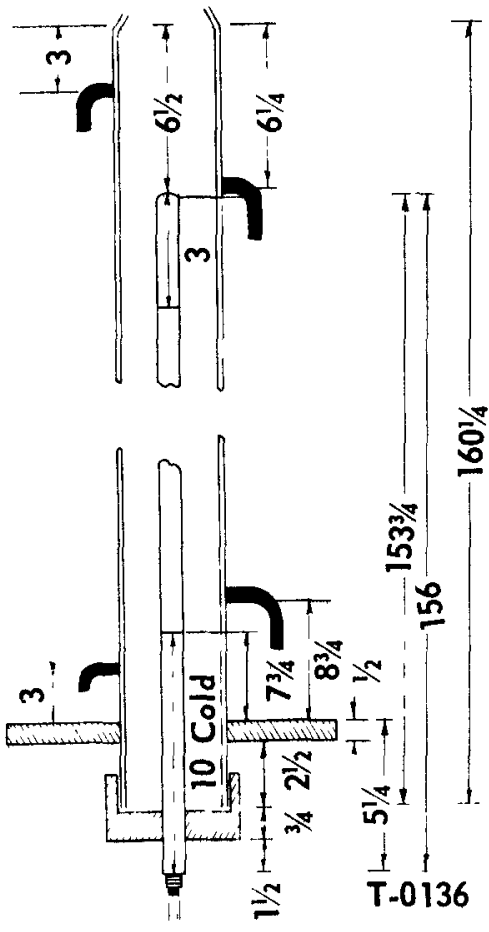

A concentration profile of xenon-124 is being built up in the system prior to drawing off the product. After two weeks, including two interruptions, the xenon- 124 has been enriched from $0.096 \%$ to $0.67 \%$ at the top of the fifth stage. The top of the cascade contained hydrogen. Analysis of gas at the top of each stage is shown in Table 3.

A calcium trap is being installed to remove the hydrogen which is accumulating in the product. Hydrogen has been taken out of the last column twice, only to reappear shortly afterward.

Prior to initial startup, the tube bundle was calibrated to determine the STP liters of gas in each stage at operating conditions (Table 2).

\section{Table 2}

Volume of Gas at Each Stage in Tube Bundle

\begin{tabular}{ccccc} 
Stage & (liters) & & Stage & (liters) \\
\cline { 5 - 6 } 1 & & & 4 & 3.54 \\
2 & 4.15 & & 5 & 3.23 \\
3 & 3.90 & & 6 & 0.79
\end{tabular}

A large interstage circulation rate is being used to achieve adequate mixing at the ends of the column. Figure 5 shows the location of the gas ports on a column. At the ton of each column, the het section of the tubular heater is adjacent to one of the gas ports, and the other port is opposite the tubular heater cold section. The circulation at the top should not be critical. At the bottom, the hot section does not extend below a gas port; thus the circulation will have to rely on ordinary diffusion in order to get the circulating gas up to the hot section of the tubular heater, approximately $3 \mathrm{in}$. The increased circulating flow rate should help since the larger stream of gas should force mixing in the bottom of the column. 
Table 3

Xenon Tube Bundle Analytical Data After 10 Days of Operation

\begin{tabular}{|c|c|c|c|c|c|c|c|}
\hline \multirow{3}{*}{$\begin{array}{l}\text { Xenon } \\
\text { Isotope }\end{array}$} & \multicolumn{7}{|c|}{ Analysis (\%) } \\
\hline & & Stage 1 & Stage 2 & Stage 3 & Stage 4 & Stage 5 & Stage 6 (product) \\
\hline & Feed & Top & Top & ToP & Top & Top & Top \\
\hline Total & & & & & & & \\
\hline Xenon & 99.80 & 99.51 & 99.37 & 99.21 & 99.16 & 60.83 & 0.00 \\
\hline 124 & $0.06^{a}$ & 0.09 & 0.10 & 0.11 & 0.16 & 0.45 & 0.00 \\
\hline 126 & 0.07 & 0.09 & 0.10 & 0.10 & 0.14 & 0.29 & 0.00 \\
\hline 128 & 1.75 & 2.38 & 2.64 & 2.47 & 3.38 & 4.92 & 0.00 \\
\hline 129 & 23.71 & 27.40 & 29.74 & 30.09 & 34.73 & 45.08 & 0.00 \\
\hline 130 & 3.87 & 4.27 & 4.52 & 4.53 & 4.91 & 5.43 & 0.00 \\
\hline 131 & 21.22 & 22.06 & 22.27 & 22.32 & 22.28 & 20.41 & 0.00 \\
\hline 132 & 27.57 & 26.94 & 26.15 & 26.11 & 24.17 & 18.46 & 0.00 \\
\hline 134 & 11.42 & 9.53 & 8.51 & 8.49 & 6.57 & 3.55 & 0.00 \\
\hline 136 & 10.33 & 7.26 & 5.98 & 5.78 & 3.66 & 1.40 & 0.00 \\
\hline $\mathrm{H}_{2}$ & 0.00 & 0.18 & 0.29 & 0.53 & 0.53 & 38.08 & 99.83 \\
\hline Other & 0.20 & 0.49 & 0.34 & 0.26 & 0.31 & 1.10 & 0.27 \\
\hline
\end{tabular}

axenon-124 should have been $0.09 \%$; the lower concentration was a result of poor circulation in the 100 liter feed tank.

Chromatography Xenon obtained as a reactor off-gas contains the radioi sotope krypton-85 as an impurity. This impurity is removed chromatographically. Continuing research in this area is directed at further reducing the krypton- 85 level while at the same time increasing the product output.

The series of separations using the synthetic Zeolite, Linde Molecular Sieve 5A, 50/60 mesh, with a nitrogen carrier gas was completed. ${ }^{2}$ The retention times of krypton and xenon were measured at $166^{\circ}, 200^{\circ}$, and $243^{\circ} \mathrm{K}$. The calculated heats were -1208 and $-1901 \mathrm{cal} / \mathrm{mole}$ for krypton and xenon, respectively. When helium was used as the carrier gas, the values obtained were -3091 and $-5127 \mathrm{cal} / \mathrm{mole}$. It is estimated that in this temperature range 0.6 of a monolayer or more of nitrogen is adsorbed on the Zeolite. As a result, the measured heats of the krypton and xenon are probably more closely related to the heats of solution

${ }^{2} M L M-1266$. 
of these gases in nitrogen than to their heats of adsorption. This would account for their values with a nitrogen carrier gas being much lower than those obtained with helium, which is negligibly adsorbed.

Some work has been done with Molecular Sieve 13X,50/60 mesh, using nitrogen for the carrier gas. The work so far has been done at $166^{\circ}$ and $243^{\circ} \mathrm{K}$. The preliminary values for the heats calculated from these two temperatures are -1240 and $-1969 \mathrm{cal} / \mathrm{mole}$ for krypton and xenon, respectively. These values are in close agreement with those found with Molecular Sieve 5A. ${ }^{3}$ Unlike Molecular Sieve 5A, however, Molecular Sieve $13 X$ exhibited far less talling. As a result, Molecular Sieve $13 X$ appears to be a promising candidate for use in a large-scale chromatographic column.

\section{THERMAL DIFFUSION RESEARCH}

Transport Coefficients Consistently large deviations from theory have been observed in separation experiments involving neon and helıum in the four $12-\mathrm{ft}$, experimental, hot-wire thermal diffusion columns. ${ }^{4}$ The deviations are observed in flow experiments only. Static separation data are in good agreement with theory.

For the flow experiments with neon, gas is circulated at a high rate across the top of the column while gas is withdrawn at a measured slow rate from the bottom of the column. In an effort to find a possible experimental explanation for the deviation from theory, it was postulated that a stagnant diffusion barrier was present at the top of the column as indicated in Figure 6. Calculations were made on the basis of the experımental data from column $E I$ to $f i n d$, for each experıment, the barrier thickness required to account for the discrepancy between theory and experıment. The results of these calculations are given in Table 4.

Table 4

Thickness of Postulated Stagnant Gas Barrier for Thermal Diffusion Experiments

\begin{tabular}{lc} 
Product Flow & Thickness of Stagnant Gas \\
(STP ml/hr) & Layer Necessary to Account \\
\hline
\end{tabular}

$\begin{array}{lll}65 & 4.2 & \\ 160 & 1.6 & \\ 191 & 1.4 & \\ 245 & 1.7 & \text { Figure 6. Postulated } \\ 444 & 2.2 & \text { stagnant gas barrier } \\ 461 & 1.7 & \text { in thermal diffusion } \\ 535 & 1.7 & \text { experiment. } \\ 623 & 1.5 & \\ 713 & 1.7 & \\ 919 & 2.0 & \\ 1197 & 2.7 & \\ 1627 & 2.0 & \\ & \text { Average }= & 1.8, \text { excluding } \\ & & \text { first point }\end{array}$

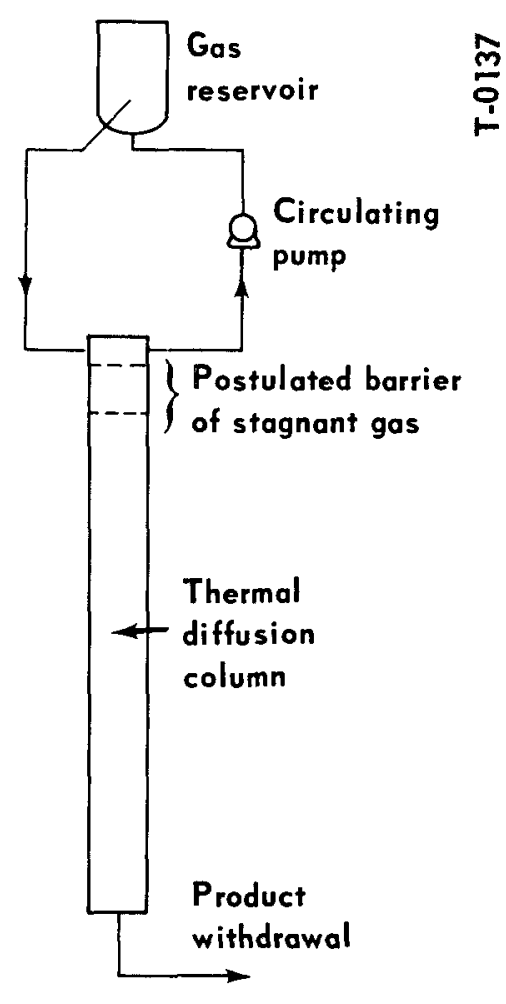

${ }^{3} M L M-1268$.

${ }^{4}$ Dimensions and other characterisics of these columns are given in MLM-1254. 
Over an extremely wide range of flow rates the observed results can be explained by the presence of a layer of stagnant gas of $1.8 \mathrm{~cm}$ thickness at the top of the experımental column. The gas ports on the column in question are very close to the top. From the dimensions of the column it does not appear that the gas is completely stagnant at the port location, however, it seems quite likely that the convective circulation rate is inadequate at this point.

Experıments are in progress to check this hypothesıs. In these experıments gas samples will be taken at several points along the column.

Collision Integrals In the Chapman-Enskog theory of gases the transport properties of a dilute gas are expressed as functions of a set of collision integrals. These integrals, which are functions of the intermolecular potential between the molecules of the gas, have been calculated for several special potential functions [e.g. the Lennard-Jones (12-6) and modified Buckıngham potentıals]. These calculations have been used extensively in evaluatıng the transport properties of gases. It has been found that these potentials are inadequate for describing the transport properties over a wide range of physical conditions. Calculation of collision integrals for more flexible potential functions are needed for this purpose. There is also a need for the calculation of collision integrals for the large number of potential functions which have been proposed in the literature. Such calculations would serve as a test of the valıdity of these potential functions.

The collision integrals are defined by the equation,

$$
\Omega^{(l, s)}(T)-\left(\frac{h l}{2 \pi \mu}\right)^{12} \int_{0}^{\infty} e^{-\gamma^{2}} x^{(2 \iota+3)} Q^{l} g d \gamma
$$

where $h$ is Boltzman's constant $\mu$ is the reduced mass of the system of two interacting particles, $\gamma^{2}=E / k T$ $-{ }^{1} 2 \mu g^{2} / k t$, and $E$ is the total energy of the system The cross section $Q l(E)$ is given by

$$
O^{l}(E)=2 \pi \int_{o}^{\infty} b\left(l-\cos ^{l} \chi\right) d b
$$

where $b$ is the impact parameter and $\chi$ is the angle of deflection in the center of mass coordinate system:

$$
\chi=\pi-2 b \int_{r_{m}}^{\infty} \frac{d r}{r^{2} F(r)}
$$

where $r_{m}$, the distance of closest approach, is the larger of the two roots of $F\left(r_{m}\right)=0$ of

$$
F(r)=\left[1-\frac{\phi(r)}{E}-\frac{b^{2}}{r^{2}}\right]^{1 / 2},
$$

and $\phi(r)$ is the interaction potential between the two particles. 


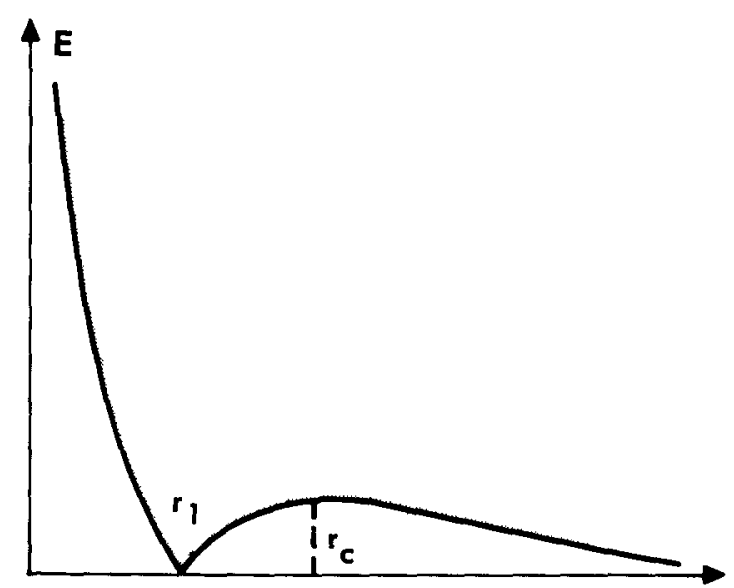

Figure 7. Region of integration for collision integrals, shown as shaded areas; $r_{c}$ is curve maximum.

$\phi(\mathbf{r})$

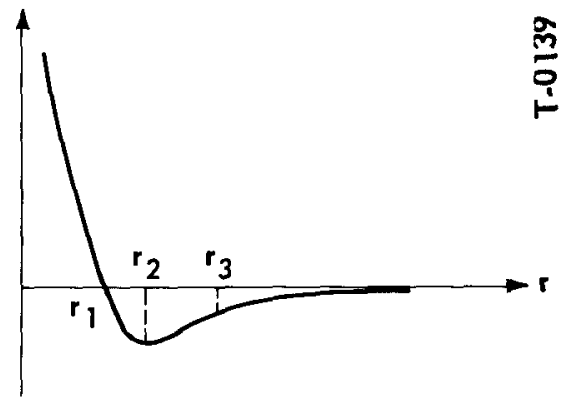

- Figure 8. Interaction potential. $\infty$ The equation $F\left(r_{m}\right)=0$ can be used to change the $\sim$ variable of integration from $b$ to $r_{m}$ in the equation $\stackrel{-}{-}$ for $Q^{l}(E)$. With this change in variable the region of integration for the collision integrals can be represented as shown in Figure 7. The portion of the boundary from $r_{m}=0$ to $r_{2}$ corresponds to the repulsive portion of the potential. The portion of the boundary from $r_{m}=r_{1}$ to $\infty$ is defined by the equations,

$E_{o}-\phi\left(r_{m}\right)-1 / 2 r_{m} \phi^{\prime}\left(r_{m}\right)=0 \quad r_{m}>r_{c}$,

$b_{o}=r_{m} \sqrt{1-\phi\left(r_{m}\right) / E_{o}} \quad r_{m}>r_{c}$,

$\boldsymbol{r}_{\mathbf{m}}$

$E_{o}\left(b_{o}^{2}-r_{m}^{2}\right)+r_{m}^{2} \phi\left(r_{m}\right)=0$

$r_{1}<r_{m}>r_{c}$, and

$3 \phi^{\prime}\left(r_{c}\right)+r_{c} \phi^{\prime \prime}\left(r_{c}\right)=0$.

The angle of deflection, which is a function of $E$ and $r_{m}$, is defined at every point in this region except on the portion of the boundary curve lying to the right of $r_{1}$. It is a continuous function of $E$ and $r_{m}$ and goes to $-\infty$ along this portion of the boundary curve. The cross section is defined as an integral with respect to $r_{m}$ at constant energy. For energies less than $E_{c}$. where $E_{c}$ is the value of the boundary curve at $r_{c}$, this integral must be broken into two parts. Finally, $\Omega^{l, s}$ is defined as an integral over the cross sections, which are functions of the energy.

The numerical techniques used in the program which has been written to calculate the collision integrals are applicable to any potential of the form shown in Figure 8. In this figure $r_{1}$ is the zero of the potential, $r_{2}$ is the minimum, and $r_{3}$ is an inflection point. These three quantities are useful in calculating the boundary curve and a subprogram has been written to calculate them by the Newton-Raphson method. This subprogram also calculates the quantity $r_{c}$ by the same method, where $r_{3}$ is used as an initial estimate to $r_{c}$.

A second subprogram has been written to calculate the boundary curve, $E_{0}=F\left(r_{m}\right)$, from the above set of equations. For a given energy, the value of $r_{m}>r_{n}$ is calculated by the Newton-Raphson method from the first equation. This value is then used in the second equation to calculate $b_{0}$. The value of $r_{1}<r_{m}<r_{e}$ is calculated by the Newton-Raphson method from the third equation. Finally, the value of $r_{m}<r_{1}$ is calculated by the same method from the equation $E_{o}-\phi\left(r_{m}\right)=O$. The initial estimates used are: $r_{c}$ for $r_{m}>r_{c}$, $r_{1}$ for $r_{1}<r_{m}<r_{c}$, and $r_{1}$ for $r_{m}<r_{1}$. These estimates are used for the first energy; for subsequent energies the values for the preceding energy are used as initial estimates. 
Smith and Munn have discussed the evaluation of the integrals for $\chi, O^{l}(F)$, and $\Omega^{(l, s)}(\mathrm{T})$ by Gaussian quadrature ${ }^{s}$ The integrals are evaluated in basically the same manner in this new program The range of energies that are needed to calculate the integral for $\Omega^{(l, s)}(T)$ by the Gauss-Laguerre quadrature formula is first found from the equations,

$$
E_{\text {max }}=k T_{\max } y_{n} \text {, and } E_{\text {mın }}=k T_{\text {mın }} y_{\hat{\imath}}
$$

where $T_{\max }$ and $T_{m \iota n}$ are the maximum and minımum temperatures for which the collision integrals are to be evaluated, and $y_{N}$ and $y_{2}$ are the largest and smallest Gauss-Laguerre abscissas. Energies are then chosen at equal logarithmic intervals in the ranges $E_{m i n}$ to $E_{c}, E_{c}$ to $2 E_{c}$, and $2 E_{c}$ to $E_{m a x}$, and $Q^{l}(E)$ is calculated at each of these energies. This table of cross sections versus energy is used in evaluating the integral for $\Omega^{(l, s)}(T)$. The cross sections that are needed in the evaluation of this integral are found by interpolation of $\log Q^{l}$ versus $\log E$. Aitken's method of interpolation is used for this purpose.

The accuracy of several of the numerical methods used in the calculation of the collision integrals has been investigated. Because it is one of the simplest potentials having the form shown in Figure 8 , the Lennard-Jones (12-6) potential has been used in most of these studies. The boundary curve for this potential has been calculated to $1 \mathrm{ppm}$. For the first energy, where $r_{1}$ and $r_{c}$ were used as the inıtial estımates, approximately 10 iterations were required for each of the three boundary values. For subsequent energies, where the values for the preceding energy were used as inıtial estımates, approximately five iteratıons were required for each of the three boundary values.

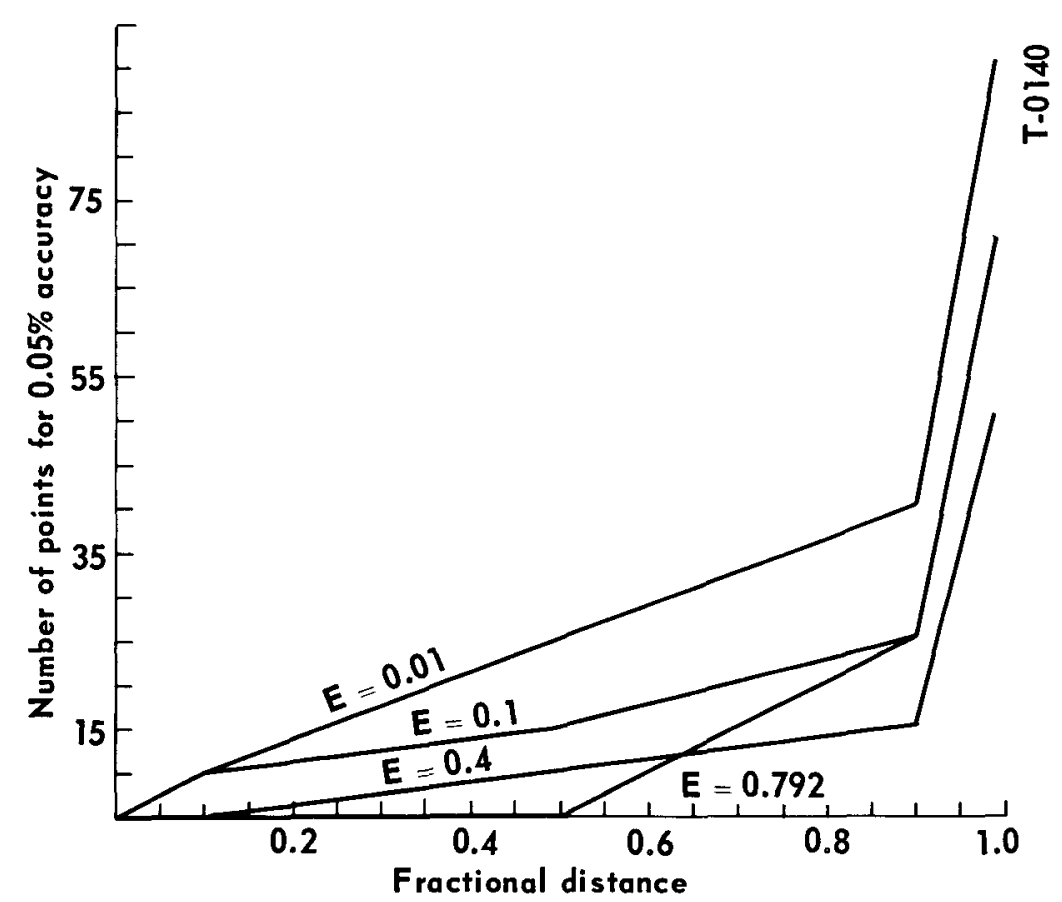

Figure 9. Number of points necessary in the Gauss-Mehler quadrature formula to calculate $\chi$.
An analysis of the integrand for $Q^{l}$ has shown that an error of $0.1 \%$ in $\chi$ introduces an error of $0.05 \%$ or less, in the integrand for $\left(1-\cos ^{l} \chi\right)$ equal to, or greater than, 0.1 . For $\left(1-\cos ^{l} \chi\right)$ less than 0.1 the error is greater. but it has little effect since $\left(1-\cos ^{l} \chi\right)$ is so small. The number of points necessary in the Gauss-Mehler quadrature formula to calculate $\chi$ accurate to $0.05 \%$ has been determıned. It was found that this number depended upon the energy and distance of closest approach. The number of points as a function of the fractional distance from the repulsive portion of the potential to the portion of the boundary curve $r_{1}<r_{m}<r_{c}$ is shown in Figure 9 for several energies less than $E_{c}$ $(=0.8)$. For energies greater than 1.0 it was found that less than 15 points were required at all distances of closest approach.

${ }^{5}$ F. J. Smith and R. J. Munn, J. Chem. Phys., 41, 3560 (1964). 
The accuracy of the interpolation technique used to obtain cross sections at arbitrary energies from a table of cross sections versus energy was checked in the following manner. Cross sections were calculated at equal logarithmic intervals in the energy: 10 cross sections per decade for $E$ less than $E_{c}, 10$ between $E_{c}$ and $2 E_{c}$, and 10 per decade for $E$ greater than $2 E_{c}$. Aitken's interpolation scheme was then used to calculate cross sections at a large number of arbitrary energies. Interpolation of both $Q^{l}$ versus $E$ and $\log Q^{l}$ versus $\log E$ was used. The accuracy of the interpolated values was determıned by the difference in the last two diagonal elements of the interpolation array. $C_{i 1}$ the average the interpolation of $\log Q^{l}$ versus $\log E$ gave significantly better results than that of $Q^{l}$ versus $E$. It was found that four points in the interpolation scheme were sufficient to calculate cross sections accurate to better than $0.2 \%$ at all energies. For a few energies, cross sections were calculated directly and compared with the interpolated values. It was found that the difference in the last two diagonal elements gave a good estımate of the error between the interpolated value and the actual value; in general, it tended to overestımate the error.

It has already been demonstrated that the computer program calculates collision integrals which are in agreement with published values. ${ }^{6}$ This work on the accuracy of the numerical techniques used in the program indicates that it will be possible to calculate values accurate to $0.1 \%$ with this program. This is more accurate than any of the experimental data on the transport properties.

Molecular Beam Scattering A velocity selector has been proposed for use in obtaınıng a monoenergetıc beam of particles in a molecular beam scattering system. Previous designs have incorporated either the multiple slotted disc ${ }^{7}$ or a radial drum selector with helical grooves. ${ }^{8,9}$ The best velocity spread has been given as between 3 and $4 \%$ with an effective open tıme of $34.8 \%$ obtained with the slotted disc type selector. ${ }^{10}$

The proposed design uses a single rotor disc which is placed in the path of the beam with its axis of rotation perpendicular to the beam axıs. The rotor can then be conveniently driven from outside the vacuum system by means of a magnetıc drive. A solenoid may be used to raise and lower the rotor from the beam. This type of rotor offers relatively simple construction and convenient drive with no moving feedthroughs. This design offers a total velocity spread of less than $1.5 \%$ with an open tıme of $38.2 \%$, somewhat better than those inentioned above.

The design of the rotor is shown in Figure 10. Five circular grooves are machined in the face of the disc and the center is bored out to the groove depth. The material to be used is 7075-T6 aluminum for its high ratio of tensile strength to density. One hundred and eighty slits are milled across the face of the disc equally spaced through the six lands produced by the grooves and the center bore. This gives 360 radial slits with a one-degree angular spacing which intersect at the center of the rotor.

The slit spacing and the outside diameter of the $d_{i s c} d_{0}$ determine the rotation $\phi$ and, hence, the angular speed $\omega$ necessary for transit of a molecule of the selected velocity $v_{0}$ across the rotor. Table 5 gives the rotor specifications.

\footnotetext{
${ }^{6}$ MLM-1274.

${ }^{7} \mathrm{H}$. A. Hostettler and R. B. Bernstein, Rev. Scr. Inst., 31, 872 (1960).

${ }^{8}$ A. E. Grosser, R. P. Iczkowskı and J. L. Margrave, Rev. Sct. Inst., 34, 116 (1963).

${ }^{9}$ S. O. Colgate, Private Communication.

${ }^{10}$ S. M. Trujlllo, P. K. and E. W. Rothe, Rev. Srt. Inst., 33, $841(1962)$.
} 

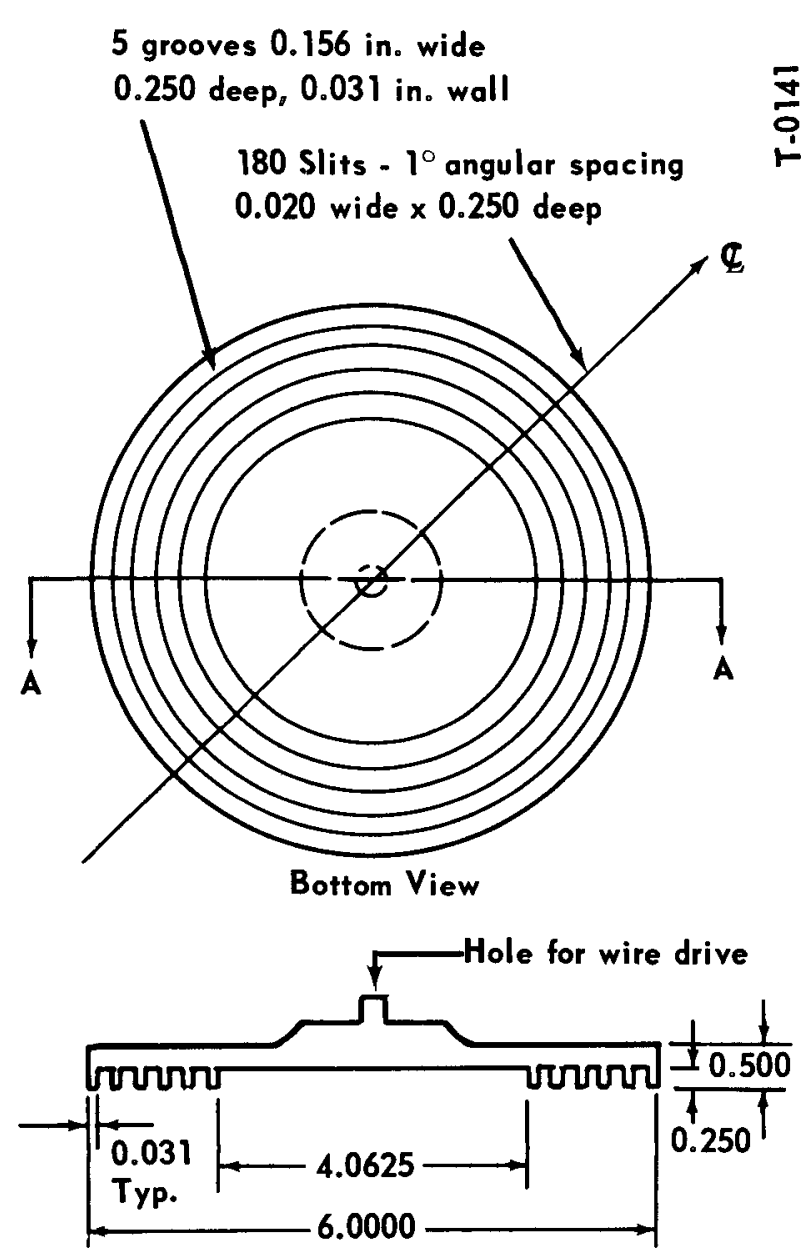

View A-A

Figure 10. Rotor design (dimensions in inches).
Table 5

$\frac{\bar{q}}{\circ}$ Rotor Specifications

$\begin{array}{ll}\text { Rotor OD, } d_{o} & 6.000 \mathrm{in} .(15.240 \mathrm{~cm}) \\ \text { Rotor ID } & 4.062 \mathrm{in} . \\ \text { Slit Width, } a & 0.020 \mathrm{in} .(.0508 \mathrm{~cm}) \\ \text { Number of Lands } & 6 \\ \text { Land Thickness, } l & 0.0312 \mathrm{in} .(.0794 \mathrm{~cm}) \\ \begin{array}{l}\text { Land Spacing } \\ \text { Number of Slits per Land }\end{array} & 360 \\ \begin{array}{l}\text { Angular Spacing of Slits } \\ \text { Minimum Distance Between }\end{array} & 1 \text { degree } \\ \text { Slits } & 0.1562 \mathrm{in} . \\ \begin{array}{l}\text { Maximum Distance Between } \\ \text { Slits }\end{array} & 0.0324 \\ \begin{array}{l}\text { Fractional Open Time } \\ \text { Rotation for One Transit, } \phi\end{array} & 32 \mathrm{deg} .(0.5585 \mathrm{rad} .) \\ \begin{array}{l}\text { Resolution } \\ \text { (Total Velocity Spread), } R T\end{array} & 0.0135\end{array}$

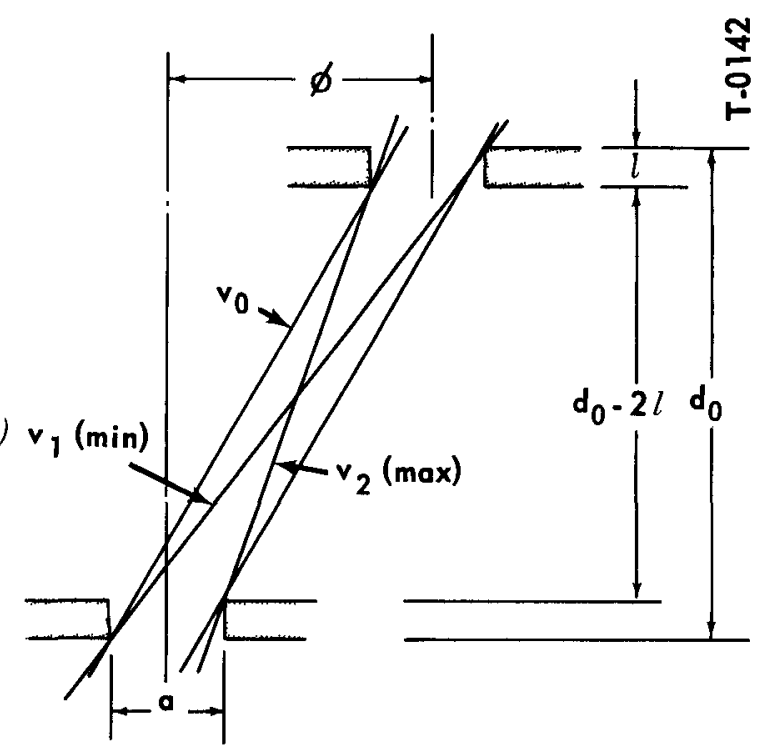

Sideband velocities are attentuated due to the multiple lands since the slit spacing decreases with diameter, giving a nonuniform slit location as seen from the transit particle.

Figure 1 I shows the representation of the maximum and minimum transmitted velocities $v_{2}(\max )$ and $v_{1}(\min ) v_{1}(\mathbf{m i n})$ with respect to the selected velocity $v_{0}$. The entry and exit slits are shown where a is the slit width and $l$ the land thickness, $\theta_{1}$ and $\theta_{2}$ are the angles subtended by the outside and inside edges of the slits with $r_{1}$ and $r_{2}$ their respective radii.

Figure 11. Representation of transmitted velocities. 
For transmission of $v_{2}$ (max) a molecule must travel the distance $\left(d_{0}-2 l\right)$ while the rotor rotates through the angle $\left(\phi-\theta_{2}\right)$ in the time $\left(\phi-a / r_{2}\right) / \omega$ where $\theta_{2} \simeq a / r_{2}$ ind $\omega$ is the angular speed of the rotor. Then,

$$
v_{\mathbf{2}}(\max )=\frac{\omega\left(d_{0}-2 l\right)}{\left(\phi-a / r_{2}\right)}
$$

Similarly, with $\phi_{1} \approx a / r_{1}: v_{1}(\min )=\omega d_{o} /\left(\phi+a / r_{1}\right)$. A molecule traveling at the selected velocity $v_{o}$ must traverse the distance $\left(d_{o}-1\right)$ while the rotor rotates through the angle $\phi$ in time $\phi / a$; hence, for $\omega(r p m)$ : $v_{o}=\left[\omega\left(d_{o}-1\right)\right] / \phi=2.843 \omega \mathrm{cm} / \mathrm{sec}$.

$$
v_{1}(\min )=\frac{\omega d_{0}}{\left(\phi+a / r_{1}\right)}
$$

The velocity resolution $R$ is given as the fractional spread in velocity,

$$
R_{T}=\frac{v_{2}(\max )-v_{2}(\min )}{v_{0}}=\frac{\phi}{\left(d_{0}-l\right)} \frac{\left(d_{0}-2 l\right)}{\left(\phi-a / r_{2}\right)}-\frac{d_{0}}{\left(\phi+a / r_{1}\right)} .
$$

The resolution corresponding to the half intensity width $R$, which is referred to in the literature is given as,

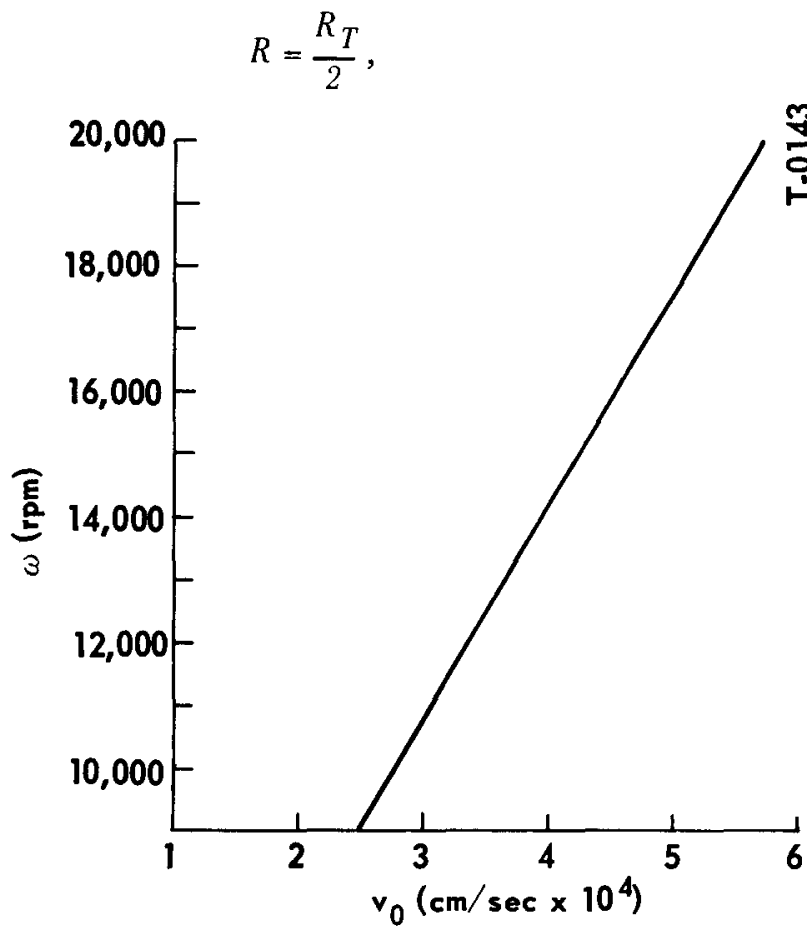

Figure 12. Velocity as a function of rotor speed for rotor design shown in Figure 10. $\frac{m}{8}$

Figure 12 shows a plot of the selected velocity $v_{0}$ against the rotor speed for this design. An increase in $v_{0}$ may be obtained by omitting some lands wi th the same angular slit spacing but sideband elimination will suffer.

In molecular beam work narrow band velocity selection is useful in studying elastic and inelastic scattering, chemical reaction kinetics and the velocity distributions of various types of beam configurations using neutral particles.

The present application is a crossed beam experiment with two thermal energy beams of neutral particles. Effusive and supersonic nozzle jet beams are to be investigated. Two such selectors will be used, one in each beam. These will be driven from a common variable phase sensitive power supply. This will allow control over the phase relation between the two beams. Each beam will be pulsed for detector synchronization.

\section{HELIUM RESEARCH}

Low-Temperature Distillation Techniques have been developed for transferring liquid helium to a pumped helium bath. These techniques will be used in an automatic liquid helium level control in the helium still being designed for the separation of helium-3 and helium-4. The helium flow to the bath was controlled by a valve mounted on the cryostat end of the helium transfer tube. The handle of this valve could be operated from outside the cryostat. It was found that a valve with reasonably smooth seating surfaces could completely stop a flow of normal liquid helium. Superfluid helium could leak through the closed valve, but the amount 
was negligible A flow of liquid helium could be restarted with relative ease after the valve had been closed Even after the transfer tube warmed up for $10 \mathrm{~m} ı \mathrm{n}$ a flow of liquid helium could be started in less than 1 min However, if the valve was below the level of the helium bath, the incoming helium gas at the start of a transfer would boil away all the helium above the valve Thus the only practical arrangement is to have the valve above the surface of the helıum bath Simılarly, the incomıng stream of warm gas or liquid should not be directed toward the surface of the bath as this also causes excessive evaporation of the bath liquid

When the valve is first opened, the relatively warm gas which comes through the valve causes some liquid helium to evaporate If the bath is being pumped to below the lambda point, the pump can easily carry away this evaporated helium But, in the case of a bath not being pumped this hard, the helium gas can build up an excessive pressure in the cryostat For this reason a pressure regulator will be needed which can quickly open the pumping line to handle the intermittent large volumes of gas

In order to continuously supply such a system with liquid helıum, it appears that an intermediate dewar between the standard storage dewar and the cryostat will be necessary. Thus, it would be possible to change storage dewars without interrupting the supply of helium to the cryostat to flush out the helium transfer lines The intermediate dewar would probably consist of a storage dewar modified to accept a transfer tube from another storage dewar, the transfer tube to the cryostat, and some sort of liquid level indicating device

Vapor Pressure Thermometry The thermomolecular pressure corrections necessary for precise vapor pressure thermometry are being investigated both theoretically and experımentally.

An alternative method of obtaınıng an equation describıng the thermomolecular pressure has been considered previously. "The molecules passing a given cross section of the tube were considered in two classes. The pressure gradient due to molecules makıng their last collısıon in the gas and those makıng their last collısion with the wall were determıned separately. The mass flow for each component was set equal to zero and then the components were added together giving

$$
\left.\frac{d P}{d T}=\frac{N_{u}}{N} \quad \frac{l}{2} \frac{P}{T}\right)+\frac{N_{2}}{N} \frac{1}{2} \frac{P}{T}\left[\frac{l 2 \eta^{2}}{\rho P} \frac{l}{r^{2}+4 K \gamma r}\right] .
$$

This equation was shown to reduce to the differential form of the Weber-Schmidt equation both in the low pressure and high pressure limıts.

Further consideration has shown that if the mass flow for the two components are added together before they are set to zero, an equation results which is identical in form to the Weber-Schmidt equation. In this rearrangement of steps, certain factors are retained which were divided out in the first considerations. Following Kennard, ${ }^{12}$ the mass flow in the free molecule case is given by

$$
Q^{\prime}{ }_{\omega}=\frac{2-f}{f} \frac{4}{3} \sqrt{\frac{2 \pi M}{R}} \mathrm{r}^{3} \frac{d}{d x}\left(\frac{P}{\sqrt{T}}\right),
$$

where $f$ is the fraction of molecules diffusely reflected from the tube wall, i.e., the accommodation coefficient, $R$ is the gas constant per mole, $r$ the tube radius and $x$ the coordinate of the tube axis. In the case where the velocity distribution function is not maxwellian, the average velocity may be represented by $v=\beta_{v}^{\prime} v(\max w e l l i a n)$. Consideration of equation (2) in this light shows that $Q_{\omega}=\beta_{\omega} Q_{\omega}^{\prime}$.

\footnotetext{
${ }^{11}$ MLM- 1266.

${ }^{12}$ E. H. Kennard, Kine tıc Theory of Gases, New York, McGraw-Hıll, 1938, pp. 291.333.
} 
The mass flow in the viscous flow case is

$$
Q_{v}=\frac{\pi}{8} \frac{P r^{4} M}{\eta R T} \frac{d P}{d x}-\frac{3 \pi}{4} \frac{\eta r^{2}}{T} \frac{d T}{d x}
$$

Now when $\lambda$ approaches $r$, but $r \geq \lambda$, the viscosity can be approximated to first order in $\lambda / r$ by ${ }^{13}$

$$
\eta=\eta_{0} \frac{1}{l+4 K(\lambda / r)} \approx \frac{(1 / 2) \rho \bar{v}_{v} \lambda}{l+4 K(\lambda / r)}
$$

where now $K=(2-f) / f$. The factor of 4 in the denomınator comes from the use of cylındrical boundary conditions. ${ }^{12}$ To be consistent with the free molecule case, $\bar{v}_{v}=\beta_{v} \bar{v}_{\text {max }}$. The term $\bar{v}_{v}$ appears in a rather complicated way in deriving the $d T / d x$ term of equation (3). Therefore, the non-maxwellian behavior in calculating this term will be represented by a multiplicative factor $\beta v^{\prime}$ In the absence of an explicit distribution function, the $\beta$ terms will be taken as undetermıned constants for the time being.

Defining $N_{w}$ and $N_{v}$ as the number of molecules passing through a given cross section of the tube, makıng their last collision with the wall and in the gas respectively, the ratio $N_{v} / N_{u}$ is

$$
\frac{N_{v}}{N_{w}}=\frac{\int \pi r^{2} d v\left(n \bar{v}_{v} / \lambda\right)}{\sqrt{2 \pi r d s\left({ }^{1} n \bar{v}_{w}\right)}}=\frac{\Omega_{1}}{\Omega_{2}} \frac{\beta_{v}}{\beta_{\omega}} \frac{2 r}{\lambda},
$$

where $\Omega_{1}$ and $\Omega_{2}$ are geometry factors, and $a=\Omega_{1} / \Omega_{2}$ will be taken as an undetermıned constant. An attempt is being made to calculate $a$.

Now, letting the mass flow of gas passing a cross section perpendicular to the tube wall be represented by $\left(N_{w} / N Q_{Q}+(N)_{v} / N\right) Q_{1}$, and setting the total flow to zero,

$$
Q_{\omega}+\frac{N_{1}}{N_{w}} Q_{v}=O
$$

or

$$
\begin{aligned}
& \frac{4}{3} \vee \frac{2 \pi M}{R} \beta_{\omega} r^{3} \frac{d}{d x}\left(\frac{P}{\sqrt{T}}\right) \\
& +\frac{\beta_{v}}{\beta_{\omega}} \frac{2 a}{K} \frac{r}{\lambda} \frac{\pi}{8} \frac{r^{4} M P}{R T \eta_{0}}\left(\begin{array}{r}
1+4 K- \\
r
\end{array}\right) \frac{\lambda}{d x}-\beta_{v}^{\prime} \frac{3 \pi}{4} \frac{r^{2} \eta_{0}}{T} \frac{l}{1+4 K(\lambda / r)} \frac{d T}{d x}=0
\end{aligned}
$$

Assumıng that $\eta_{0}=1 / 2 \beta_{v} \rho \bar{v} \lambda$ and $P_{r} / \eta_{0}=\pi / 4\left(1 / \beta_{v}\right)(r / \lambda)$, the following algebraic steps will reduce equation (6) to the form of the Weber-Schmidt equation.

Takıng the derivative indicated in the first term of equation (6) and dividing through by $4 / 3 \sqrt{2 \pi M} / R \beta_{f} r^{3}$,

$$
\begin{aligned}
& \frac{d P}{d x}-\frac{1}{2} \frac{P}{T} \frac{d T}{d x} \\
& +\frac{3}{4} \frac{\beta_{v}}{\beta_{\omega}^{2}} \sqrt{\frac{R T}{2 \pi M}} \frac{2 a}{K} \frac{r}{\lambda}\left\lceil\frac{\pi M}{8 R T} \frac{P r}{\eta_{0}}\left|1+4 K \frac{\lambda}{r}\right| \frac{d P}{d x}-\frac{1}{2} \frac{P}{T} \frac{3 \pi}{2} \frac{\beta_{v}^{\prime} \eta_{0}}{P r}\left|\frac{1}{l+4 K(\lambda / r) \mid}\right| \frac{d T}{d x} \mid=0\right.
\end{aligned}
$$

\footnotetext{
${ }^{13}$ S. Chapman and T. C. Cowling, Mathematical Theory of Non-uniform Gases, Cambridge University Press, 1953, pp. $101-03$.
} 
Using the relation

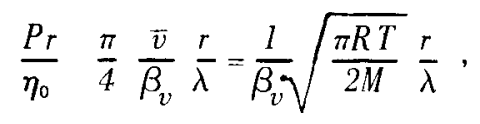

it becomes,

$$
\begin{aligned}
& \frac{d P}{d x}-\frac{1}{2} \frac{P}{T} \frac{d T}{d x}+
\end{aligned}
$$

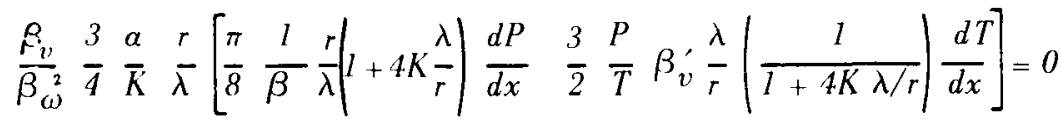

or

$$
\left[1+\frac{3 \pi}{32} \frac{\alpha}{K} \frac{l}{\beta_{f}^{2}} \frac{r^{2}}{\lambda^{2}}\left(l+4 K \frac{\lambda}{r}\right)\right] \frac{d P}{d x}=\frac{l}{2} \frac{P}{T}\left[l+\frac{9}{4} \frac{a}{K} \frac{\beta_{v}^{\prime} \beta_{v}}{\beta_{\omega}^{2}}\left(\frac{l}{l+4 K \lambda / r}\right) \frac{d T}{d x}\right] .
$$

On the right side of the above equation, using the fact,

$$
l+a\left|\frac{1}{l+b x}\right|=(1+a) \frac{l+b /(1+a) x}{l+b x}
$$

and forming $d P / d T$,

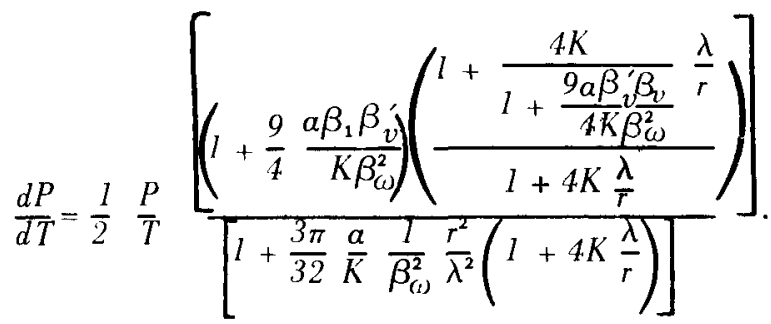

Since the combinations $9 / 4 \alpha / \beta_{f}^{2}$ and $\beta_{v} \beta_{v}^{\prime}$ always appear together, they will be denoted by $\gamma$ and $\beta$, respectively. These two combinations have separate physical meanings. Thus, equation (7) becomes

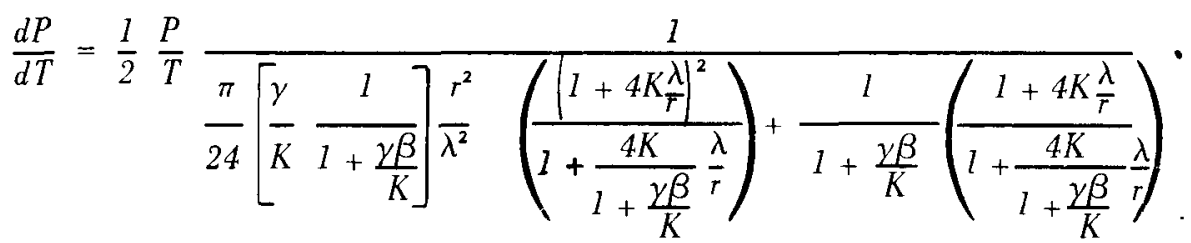

This equation can be put in to the differential form of the Weber-Schmidt equation by performing the division indicated in the first term of the denominator:

$$
\frac{\left(1+4 K \frac{\lambda}{r}\right)^{2}}{1+\frac{4 K}{1+\frac{\gamma \beta}{K}} \frac{\lambda}{r}}=1+4 K\left(\frac{1+2 \frac{\gamma \beta}{K}}{1+\frac{\gamma \beta}{K}}\right) \frac{16 K^{2}\left(\frac{\gamma \beta}{K}\right)^{2}}{r}+\frac{\frac{\lambda^{2}}{r^{2}}}{\left.1+\frac{\gamma \beta}{K}\right)^{2}} \frac{\lambda}{1+\frac{\gamma \beta}{K}} \frac{\lambda}{r}
$$


It can be seen that $\left(\lambda^{2} / r^{2}\right)$ divides out when the above expression is put into equation (8) giving

$$
\frac{d P}{d T}=\frac{l}{2} \frac{P}{T}\left\{\frac{\pi}{24} \frac{\gamma}{K} \frac{1}{1+\frac{\gamma \beta}{K}} \frac{r^{2}}{\lambda^{2}}\left[1+t K\left(\frac{1+2 \frac{\gamma \beta}{K}}{l+\frac{\gamma \beta}{K}}\right) \frac{\lambda}{r}\right]+\left[\frac{\frac{2 \pi}{3} K \gamma\left(\frac{\gamma \beta}{K}\right)^{2}}{1 k\left(1+\frac{\gamma \beta}{K}\right)^{2}} \frac{r}{\lambda}\right]\right\}^{-1}
$$

It is now clear that equation (9) is of the same form as the differential form of the Weber-Schmidt equation.

$$
\frac{d P}{d T}=\frac{l}{2} \frac{P}{T} \frac{l}{\frac{\pi}{2 t} \frac{l}{K_{1}} \frac{r^{2}}{\lambda^{2}}\left[l+1 K_{\frac{\lambda}{2}}\right]+\left[\frac{l+g \frac{r}{\lambda}}{l+h \frac{r}{\lambda}}\right]}
$$

where now, in terms of $k, \gamma$ and $\beta$, the Weber-Schmidt constants are

$$
\begin{array}{ll}
h_{1}=\beta+\frac{K}{\gamma}, & K_{2}=K \frac{l+2 \gamma \beta / K}{l+\gamma \beta / K} \\
g=\frac{l}{4 h} \frac{\frac{2 \pi}{3} K \gamma\left(\frac{\gamma \beta}{h}\right)^{2}}{\left(1+\frac{\gamma \beta}{h}\right)^{2}}, & \text { and } h=\frac{l}{4 K}\left(1+\frac{\gamma \beta}{K}\right) .
\end{array}
$$

It is helpful here to review the physical significance of $k, \gamma$, and $\beta$. The term $K=(2-f) / f$ is a measure of the fraction of molecules reflected diffusely from the tube wall. The term $\gamma=9 \alpha / 4 \beta_{\omega}^{2}$ is a measure of the deviation from the maxwellian distribution of the molecules making their last collision with the wall. There is also a geometry factor $\alpha$ in $\gamma$. The term $\beta=\beta_{v}^{\prime} \beta_{v}$ is a measure of the deviation from the maxwellian distribution of the molecules making their last collision in the gas.

As a comparison of the present work with the Weber-Schmidt constants, values of $K_{1}, K_{2}$ and $g / h$ calculated from ( 11 ) were compared with the experimental fit to the data given by Weber and Schmıdt. The results are given in Table 6.

\section{Table 6}

\section{Comparison of Mound Values with Weber-Schmidt Constants}

$\begin{array}{lcccc} & \underline{K_{1}} & & K_{2} & \frac{\mathrm{g} / h}{} \\ \text { Taken from Weber-Schmidt data } & & 1.36 & 1.68 & 1.25 \\ \text { Taken from Knudsen data } & 1.32 & 1.72 & 1.18 \\ \text { Calculated } & \text { from equation (11) } & 1.33 & 1.74 & 1.14\end{array}$

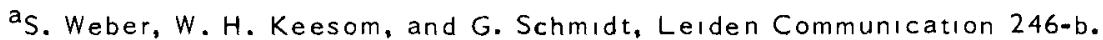
busing $K=1.0, \beta=1.0$, and $a^{\prime} \beta^{2}=1.3$, which are physically reasonable values. 
In view of the differences between the Mound data and literature values, calculations are now in progress to vary $K, \beta$, and $y$ to see if a fit can also be obtained with the Mound data. Then some physical insight into the differences between the thermomolecular pressures measured by different investigators may be gained.

Two simplified versıons of the Weber-Schmidt differentıal equation have been investigated. These are applicable only to the high pressure region when the mean free path is very small compared to the dimensions of the tube. The first equation was obtained ${ }^{14}$ to test the effect of the gas viscosity on the predicted thermomolecular pressure differences since it was observed that the viscosity index $(n=0.147)$ used by Weber and Schmidt did not agree with that computed using more recent, experimentally determined viscosities. ${ }^{15} \mathrm{~A}$ least squares fit of the data indicated a value of $n=0.155$ from $6.5^{\circ} \mathrm{K}$ to $300^{\circ} \mathrm{K}$ and $n=0.518$ from $1^{\circ} \mathrm{K}$ to $6.5^{\circ} \mathrm{K}$. The equation,

$$
p_{w}=\left[\frac{12 R}{M \Gamma^{2}} \int_{T_{c}}^{T} \eta^{2}(T) d T+p_{c}^{2}\right]^{1 / 2}
$$

was solved using experimental values of the viscosity and the results are compared in Figure 13 to the Weber-Schmidt equa on and the smoothed experımental data obtained at Mound.

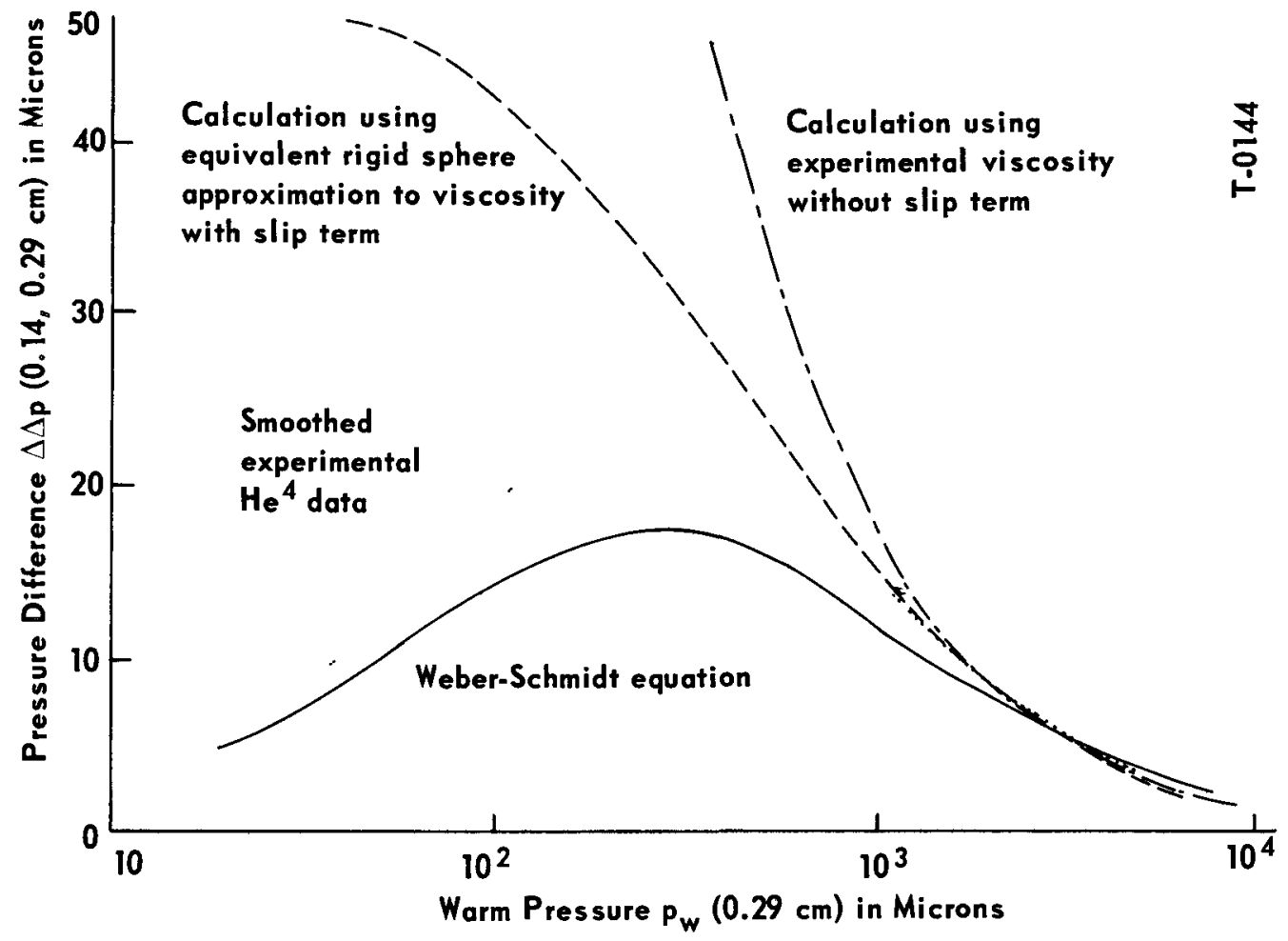

Figure 13. Comparison of Mound pressure data and data obtained with the Weber-Schmidt equation.

\footnotetext{
${ }^{14}$ MLM- $\mid 231$.

${ }^{15}$ D. P. Kelly and W. J. Haubach, MLM-1|6I.
} 
The differential equation was also solved with the slip term included, ${ }^{16}$ (the slip term appears a second time as indicated previously) which arose from the Maxwell-Hettner expression for the "creep" velocity. A rigid sphere model was assumed to adequately represent the temperature dependence of the viscosity. The solution to this equation is

$$
\begin{aligned}
\ln \frac{T_{2}}{T} & =\frac{1}{2} \ln \left(\frac{8 r^{2} \sigma^{2} N{p_{1}}^{2} / T_{1}{ }^{2}+5 \sqrt{2} R r p_{1} / T_{1}-75 R^{2} / 16 \pi \sigma^{2} N}{8 r^{2} \sigma^{2} N p_{2}{ }^{2} / T_{2}{ }^{2}+5 \sqrt{2} R r p_{2} / T_{2}-75 R^{2} / 16 \pi \sigma^{2} N}\right) \\
& +\sqrt{\frac{\pi}{4 \pi+12}}\left[\ln \left(\frac{16 r^{2} \sigma^{2} N p_{1} / T_{1}+5(\sqrt{2}-\sqrt{2+6 / \pi}) R r}{\left.16 r^{2} \sigma^{2} N p_{2} / T_{2}+5 \sqrt{2}-\sqrt{2+6 / \pi}\right) R r}\right)\right] \\
& -\ln \left(\frac{16 r^{2} \sigma^{2} N p_{1} / T_{1}+5(\sqrt{2}+\sqrt{2+6 / \pi}) R r}{16 r^{2} \sigma^{2} N p_{2} / T_{2}+5(\sqrt{2}+\sqrt{2+6 / \pi}) R r}\right)
\end{aligned}
$$

Calculations have shown that the shape of the curve is not particularly sensitive to the power index used and the correct magnitude for the effect may be obtained by using "effective" rigid sphere collision diameters calculated from realistic collision cross sections by

$$
\sigma_{e f f}=\left(\frac{Q^{(l)}}{\pi}\right)^{1 / 2}
$$

Cross sections were calculated at several temperatures for a modified-Buckingham potential with parameters reported by Mason and Rice. ${ }^{17}$ The results are shown in Table 7 . The results are realistic with respect to

\begin{tabular}{|c|c|c|c|c|c|c|c|c|}
\hline \multirow[b]{2}{*}{$T$} & \multicolumn{8}{|c|}{$\begin{aligned} r_{1} & =3.135 ; \alpha=12.4 \\
\epsilon / K & =9.16 ; 1=2\end{aligned}$} \\
\hline & $\left({ }^{\circ} \mathrm{K}\right)$ & 30 & 50 & 100 & 150 & 200 & 250 & 300 \\
\hline$Q^{(l)}$ & $\left(A^{2}\right)$ & 15.85 & 14.24 & 12.51 & 11.60 & 10.98 & 10.50 & 10.12 \\
\hline$\sigma_{e f f}$ & (A) & 2.25 & 2.13 & 2.00 & 1.92 & 1.87 & 1.83 & 1.79 \\
\hline
\end{tabular}
the intermolecular potential, but they were obtained classically.

Table 7

\section{Effective Rigid Sphere Diameter From Collision Cross Sections}

It can be seen in Table 7 that a value of $\sigma_{e f f}=2.0$ A adequately represents the experimental data. A somewhat larger value $(\approx 2.1 \mathrm{~A})$ is necessary to fit the Weber-Schmidt equation. However, it is unlikely that all of the gas in the experimental system is at the very low temperature necessary to yield a large value of the collision radius, and this is impossible in the runs made at $T_{c}=77^{\circ} \mathrm{K}$. In addition, the most recent experimental data taken at Mound (also considered to be the most reliable) cross the Weber Schmidt curve at about 3000 microns of $p_{w}$. It appears that the experimental data in the high pressure region are in better agreement with the two previous equations than with the Weber-Schmidt calculation.

\footnotetext{
${ }^{16}$ MLM- 1266.

${ }^{17}$ E. A. Mason and W. E. Rice, J. Chem. Phys., 22 (1954).
} 


\section{ANALYTICAL AND INSTRUMENTATION}

Methods of analyzing elements and compounds are being developed to support the programs at Mound Laboratory. These methods include instrumental techniques and standard wet methods.

\section{EMISSION SPECTROSCOPIC ANALYSIS}

Beryllıum in Air A new direct reader emission spectroscopic procedure was developed for the determination of beryllium in air samples. Palladium was selected as the internal standard because it was available on the direct reader and because it was probably not a contamınant in the samples.

The intensity of the palladium line increased $w_{1}$ th an increase in the concentration of beryllium in the sample. To mınımıze the inter-elemental effect, varıous bufferıng agents were added. $\mathrm{A} 10 \% \mathrm{BaCO}_{3}$ in graphite mıx was a satısfactory suppressor. The palladıum intensıty did not vary sıgnificantly when the beryllium concentration was varied from $0.1 \mu \mathrm{g}$ to $10 \mu \mathrm{g}$. To improve precision and increase the sensitivity of detection, an argon-oxygen atmosphere was employed. With this method it was possible to determine I $\mu g$ of beryllium with an average deviation of $\pm 0.1 \mu \mathrm{g}$.

Impurities in Gold A direct reader procedure for the quantıtatıve determination of impurıties in gold was also completed. The method is capable of detecting impurity levels below $0.00006 \mathrm{mg}$. The use of a $20 \%$ $\mathrm{BaCO}_{3}$ in graphite mix and a controlled atmosphere of argon-oxygen improved the limits of detection of the impurities two- to threefold. 
- 


\section{ORGANIC RESEARCH}

In support of other programs at Mound Laboratory, research is being conducted on filled plastics, foams and adhesives for specialized applications.

\section{ADHESIVE SHRINKAGE STUDIES}

The total shrınkage of Eastman 910 Adhesıve (methyl 2-cyanoacrylate) was determıned under thermal, freeradical and anionic polymerization conditions. Samples initiated thermally or by free-radical conditions were first stabilized against anionic polymerization by the addition of a boron trifluoride-2 acetic acid complex. ${ }^{18}$ The complex was prepared by bubbling boron trifluoride slowly through a layer of mercury into glacial acetıc acıd. The product was distilled under reduced pressure in a nitrogen atmosphere. Adhesive samples were stabilized by the addition of $0.05 \mathrm{ml}$ of boron trifluoride- 2 acetic acid complex for each $10 \mathrm{ml}$ of sample.

The total shrinkages were evaluated by determining the densities of the uncured and cured adhesive at room temperature using a modification of the procedure of Moll and Spencer. ${ }^{19}$ This value (In percent) is given by

$$
S=\frac{D_{2}-D_{1}}{D_{2}} \times 100
$$

where $D_{1}$ is the density of the uncured sample at room temperature $(1.098 \mathrm{~g} / \mathrm{cc})$ and $D_{2}$ is the density of the cured sample at room temperature. The volume of each sample was determined by its displacement of distilled water at a known temperature. From this value and the weight of the sample, the density $D_{2}$ was calculated.

Volumetric flasks, previously coated with 225 Mold Release, were employed as molds for the shrinkage determinations of the thermally and free-radically initiated samples. In all cases the cured samples were not of uniform texture; they contained both regions of a more dense yellow-brown material and less dense light yellow material. The bottom section of each flask, however, always consisted of uniform yellow-brown plastIC and this section was used for density determinations. Anionic polymerization was accomplished by coatIng a thın $f_{1} / m$ of the adhesive on a brass strip and allowing the water vapor present, actıng as a weak base, to cure the sample. In this case the cured sample was white. Table 8 lists the same preparation, initiator used, cure temperature, density of cured sample and total shrinkage.

The values found for the total shrinkage of the adhesive did not vary with the polymerization conditions employed. Graham et al! $!^{8}$ polymerized methyl 2-cyanoacrylate of high purity under freeradical conditions obtaınıng polymer with a densıty of $1.304 \mathrm{~g} / \mathrm{cc}$ at $25^{\circ} \mathrm{C}$, which represents a total shrınkage of $15.6 \%$.

\footnotetext{
${ }^{18}$ R. H. Graham et al., J. App. Poly. Sck., 4, 231 (1960).

${ }^{19}$ R. E. Moll and J. B. Spencer. Sandia Corporation Report, Auzust 9, 1962, p. 8.
} 
Table 8

Shrinkage of Eastman 910 Adhesive on Curing

\begin{tabular}{|c|c|c|c|c|c|}
\hline $\begin{array}{c}\text { Sample } \\
\text { Preparation }\end{array}$ & Initiator & $\begin{array}{c}\text { Cure } \\
\text { Temp. } \\
\left({ }^{\circ} \mathrm{C}\right)\end{array}$ & $\begin{array}{c}\text { Reaction } \\
\text { Time } \\
\text { (days) }\end{array}$ & $\begin{array}{c}\text { Final } \\
\text { Density } \\
\left(D_{2}\right) \\
(g / C c) \\
\end{array}$ & $\begin{array}{c}\text { Total } \\
\text { Shrinkage } \\
(\%)\end{array}$ \\
\hline \multicolumn{6}{|l|}{ Stabilized with } \\
\hline $\mathrm{BF}_{3} \cdot 2 \mathrm{CH}_{3} \mathrm{COOH}$ & None & $70^{\circ}$ & 7 & 1.297 & 15.3 \\
\hline \multicolumn{6}{|l|}{ Stabillzed with } \\
\hline $\mathrm{BF}_{3} \cdot 2 \mathrm{CH}_{3} \mathrm{COOH}$ & None & $70^{\circ}$ & 7 & 1.297 & 15.3 \\
\hline \multicolumn{6}{|l|}{ Stabilized with } \\
\hline $\mathrm{BF}_{3} \cdot 2 \mathrm{CH}_{3} \mathrm{COOH}$ & None & $70^{\circ}$ & 7 & 1.301 & 15.6 \\
\hline Stabilized with & Benzoyl & & & & \\
\hline $\mathrm{BF}_{3} \cdot 2 \mathrm{CH}_{3} \mathrm{COOH}$ & peroxide & $70^{\circ}$ & 3 & 1.304 & 15.8 \\
\hline Stabilized with & Benzoyl & & & & \\
\hline $\mathrm{BF}_{3} \cdot 2 \mathrm{CH}_{3} \mathrm{COOH}$ & peroxide & $70^{\circ}$ & 3 & 1.298 & 15.4 \\
\hline Stabilized with & $a, a^{1}-$ Azodiiso- & & & & \\
\hline $\mathrm{BF}_{3} \cdot 2 \mathrm{CH}_{3} \mathrm{COOH}$ & butyronitrile & $60^{\circ}$ & 1.5 & 1.298 & 15.4 \\
\hline $\begin{array}{l}\text { Stabilized with } \\
\mathrm{BF}_{3} \cdot 2 \mathrm{CH}_{3} \mathrm{COOH}\end{array}$ & $\begin{array}{l}a, a^{1}-\text { Azodiiso- } \\
\text { butyronitrile }\end{array}$ & $60^{\circ}$ & 1.5 & 1.299 & 15.5 \\
\hline $\begin{array}{l}\text { A thin layer of } \\
\text { nonstabilized } \\
\text { adhesive was } \\
\text { coated on a brass } \\
\text { strip. }\end{array}$ & $\begin{array}{l}\text { (None) } \\
\text { moisture }\end{array}$ & $25^{\circ}$ & $\sim \mathrm{hr}$ & 1.300 & 15.5 \\
\hline $\begin{array}{l}\text { A thin layer of } \\
\text { nonstabilized } \\
\text { adhesive was } \\
\text { coated on a brass } \\
\text { strip. }\end{array}$ & $\begin{array}{l}\text { (None) } \\
\text { moisture }\end{array}$ & $25^{\circ}$ & $\mu h r$ & -1.291 & 14.9 \\
\hline
\end{tabular}

